\title{
Effect of Fiber Content and Screw Speed on Mechanical Characterization of Sisal Fiber Reinforced Polypropylene Composites
}

\author{
Somashekar S, Shanthakumar G C
}

\begin{abstract}
The present paper researches the impact of differing fiber content and speed on tensile flexural, HDT and effect properties of characteristic fiber (sisal) fortified polypropylene composites (NF). The support fiber (Sisal-Fiber) was gathered from the foliage of locally accessible tree through the procedure of water retting and mechanical extraction. Poor adhesion among fiber and matrix is regularly experienced issue in characteristic fiber-strengthened composites and to conquer this issue, physical and substance medicines were performed for surface adjustment of fibers. The expansion of compatibilizer to the matrix like, is enhanced the adhesion attributes of the fiber. The outcomes it proposes that the high level of fibers combined with a higher screw speed improves the mechanical properties of the Sisal Fiber-Polypropylene plastic composite due to a high interaction between the fiber and the matrix and an even distribution of the fiber in the matrix.
\end{abstract}

Keywords-Sisal; PolyPropylene; natural fiber; Plastic composite.

\section{INTRODUCTION}

The absence of oil assets and ecological contamination have raised developing interests in the abuse of inexhaustible crude materials which are green and maintainable [1]. Among the different accessible materials an impressive consideration has been given to starch because of its innate points of interest emerging from ease, inexhaustibility and biodegradabihty [2]. In any case, local starch has inconveniences as far as its mechanical properties, water opposition, processability and warm dependability [3]. With the end goal to defeat the above disadvantages characteristic filaments have been investigated as support materials and in addition producing the end materials in a naturally well disposed way [4 It is imperative that among the customary strands the mechanical properties of flax, hemp and sisal resemble glass filaments considering their elasticity and Young's modulus [5].

Yet characteristic strands invigorated starch composites don't match persistent filaments in solidness and quality the mind blowing processability and insignificant exertion settle on them a first decision in the realistic applications [5 $61 \mathrm{As}$ it is understood that the execution of composites is controlled by the properties of individual parts and interfacial connection among fiber and structure. It is especially seen that the interfacial bond has critical effect on the properties of the resultant composites. In any case,

Revised Manuscript Received on April 12, 2019.

Somashekar S,Department of Mechanical Engineering, T John Institute of Technology, NICE Ring Rd, Basavanapura, Bengaluru, Karnataka 560076, India. (E-mail: somashekars@gmail.com)

Shanthakumar $\mathbf{G}$ C, School of Mechanical and Industrial Engineering,Addis Ababa Institute of Technology, Addis Ababa, Ethiopia. (E-mail: skdevaramane@gmail.com) characteristic filaments ha e constraints, for instance, low similarity and poor interfacial grasp with lattice [7]. To beat these issues, a few means have been connected to the change of the interfacial attachment between normal fiber and polymer [8-10].

The use of natural fiber reinforced composite materials in the automobile sector [11-13] and in the construction business [14] is exponentially growing. The panels made from natural fiber reinforced composites are high in strength with relatively low weight. Another major advantage of these panels is that they can be recycled endlessly.

Injection molding and extrusion arc the two most commonly used methods of producing natural fiber reinforced thermoplastic composites [15]. But these techniques arc highly expensive and degrade the fibers during processing. This article deals with producing panels with sisal fiber reinforcements in thermoplastic composites and their mechanical strength.

\section{A. Fibers}

Fiber strands give the quality and firmness and go about as support $\mathrm{m}$ a fiber reinforced composite material Manufactured filaments for example. glass, carbon and aramid. fortify the larger part of polymer composite materials right now created. $\mathrm{Be}$ that as it may. ecological concerns related with manufactured fibers and vulnerabilities in oil costs have prompted escalated investigations on the reasonableness of natural fibers as support.

Natural fibers arc composites of void cellulose fibrils held together by a lignin and hemicellulose matrix Each fibril is made of a layered structure involving a thin basic divider encasing a thick helper divider. The helper divider is contained three layers and the thick focus layer chooses the mechanical properties of the fiber. The mechanical properties of these strands are dependent on the cellulose content in the fiber. the level of polymerization of the cellulose and the microfibril point [16-17]. Higher versatility and modulus can be accomplished in fibers with higher cellulose content, more elevated amount of polymerization and a lower microfibrillar point. The mechanical properties of the fibers fluctuate in their properties relying upon the length of the fiber and the separation between the filaments in the fiber. The hydroxyl groups in the cellulose of the fiber essentially make the fiber hydrophilic. Sisal filaments were decided for this examination by virtue of their respectably high caliber and modulus [18] 


\section{EFFECT OF FIBER CONTENT AND SCREW SPEED ON MECHANICAL CHARACTERIZATION OF SISAL FIBER REINFORCED POLYPROPYLENE COMPOSITES}

\section{B. Matrix}

The major function of the matrix is to connect the fibers together and exchange the load applied on it with the filaments. Another important function of the matrix is that it shields the filaments against harmful ecological effects. At the point when a composite material is framed into a shape or a profile, the lattice shields the fibers from harm. The properties of accessible polymers, thermosets and thermoplastics, make them perfect grids.

The matrix in a natural fiber reinforced composite should have a lower melting point than that of the strands and the fiber should have high wettability. These two factors highly impact the performance of the composite and also its life.

The prerequisites for the network in a sisal fiberstrengthened thermoplastic composite are:

- Melting point ought to be lower than the corruption temperature of the strands.

- Fiber wettability must be great. investigation on account of its great property go, low melting temperature and genuinely great fiber wettability [18].

\section{MATERIAL AND METHODS:}

\section{A. Composite Production}

A twin screw extruder was $u, d$ to extrude the sisal fiberpolypropylene mixture at 10,20 and $30 \%$ fiber mass fraction and screw speed of 100, 200 RPM. The working temperature was set in the range of $200^{\circ} \mathrm{C}$ and $230^{\circ} \mathrm{C}$. To guarantee an all the more uniformly circulated temperature all through the procedure the temperatures of all the four zones of the barrel were meticulously checked. The extruder load and the rotational speed of the tighten were adjusted like way. After ejection, tests of the extrudate were accumulated for examination.

\section{B. Sample Preparation:}

After the extrusion process, the sisal fiber composite specimen was prepared as per the ASTM standard given in Table 1 and the samples for the mechanical testing are as shown figures 1-3.

\section{TABLE I. ASTM STANDARDS FOR SPECIMEN} TESTING

\begin{tabular}{|c|c|c|}
\hline S1 No. & Test Name & Standard used \\
\hline 1 & Tensile test & $\begin{array}{c}\text { ASTM D638 Type } \\
\text { I }\end{array}$ \\
\hline 2 & Heat Deflection Test & ASTM D 648 \\
\hline 3 & Flexural Test & ASTM D 7264 \\
\hline 4 & $\begin{array}{c}\text { Impact Test (Un- } \\
\text { notched) }\end{array}$ & ASTM D 4812 \\
\hline
\end{tabular}

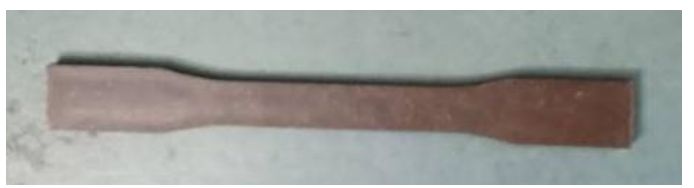

Fig. 1. Sisal Fiber composite sample as per ASTM standard for tensile testing
Polypropylene was picked as the grid material in this

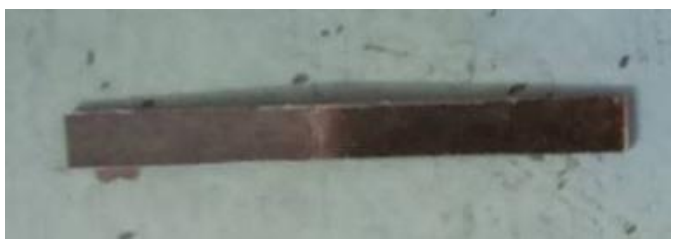

Fig. 2. Sisal Fiber composite sample for three point flexural testing

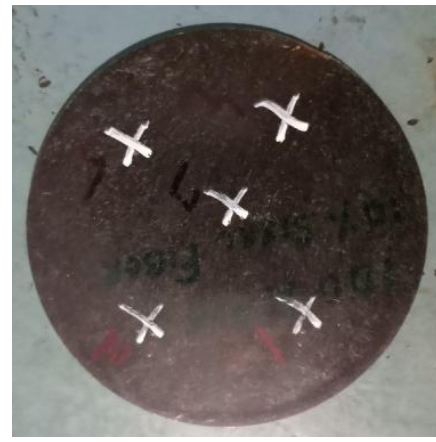

Fig. 3. Sisal Fiber composite samples for hardness testing with five points marked for testing

Table 2 gives the parameters under which the samples were prepared. The fiber mass percentage and the screw speed are considered for the sample preparation. A Xylene test was conducted on the prepared specimen to confirm their compositions.

\section{TABLE II.SELECTION OF COMPOSITION FOR} SPECIMEN PREPARATION.

\begin{tabular}{|c|c|c|c|c|c|}
\hline S1 & Sample & $\begin{array}{c}\text { Mass } \\
\text { ID } \\
\text { Percen } \\
\text { tage }\end{array}$ & $\begin{array}{c}\text { Compatib } \\
\text { ilizer }\end{array}$ & $\begin{array}{c}\text { Polyprop } \\
\text { ylene } \\
\text { Matrix }\end{array}$ & $\begin{array}{c}\text { Screw } \\
\text { speed }\end{array}$ \\
\cline { 3 - 6 } 1 & $\begin{array}{c}\text { PP10S } \\
\text { F100 }\end{array}$ & 10 & 4 & 86 & 100 \\
\hline 2 & $\begin{array}{c}\text { PP20S } \\
\text { F100 }\end{array}$ & 20 & 4 & 76 & 100 \\
\hline 3 & $\begin{array}{c}\text { PP20S } \\
\text { F200 }\end{array}$ & 20 & 4 & 76 & 200 \\
\hline 4 & $\begin{array}{c}\text { PP30S } \\
\text { F200 }\end{array}$ & 30 & 4 & 66 & 200 \\
\hline
\end{tabular}

\section{RESULTS}

Initially, the prepared specimen was analyzed under SEM to identify the surface topology under a scanning electron microscope with 2000X and 5000X magnifications.

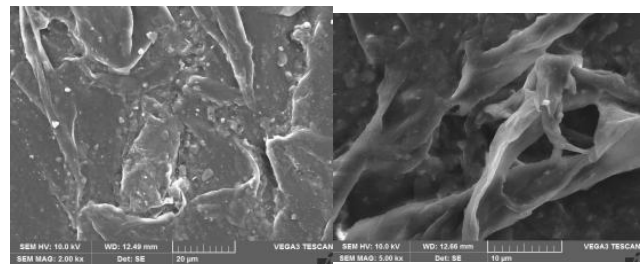

Fig. 4. Scanning Electron Microscopy (SEM) images (2000X and 5000X) of fractured PP10SF100 


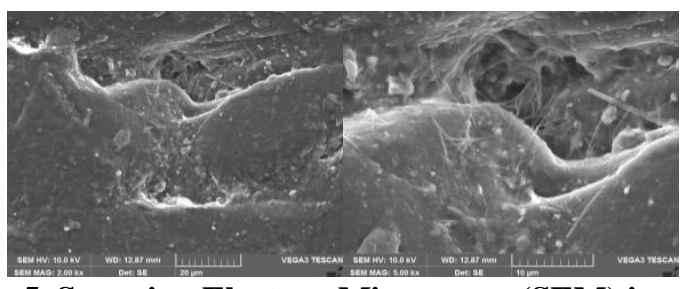

Fig. 5. Scanning Electron Microscopy (SEM) images (2000X and 5000X) of fractured PP20SF100

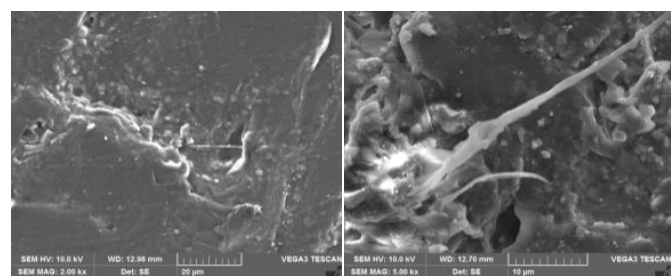

Fig. 6. Scanning Electron Microscopy (SEM) images (2000X and 5000X) of fractured PP20SF200

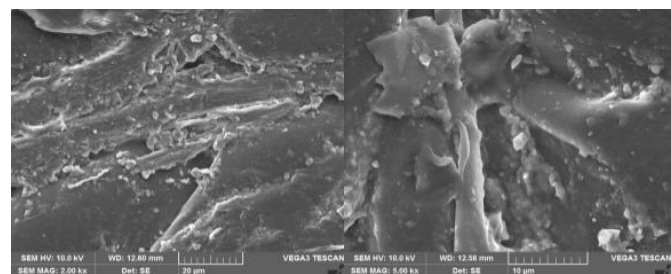

Fig. 7. Scanning Electron Microscopy (SEM) images (2000X and 5000X) of fractured PP30SF200

A previous study indicated that the key point to phase morphology composed of the continuous phase and dispersed phase is determined by the ratio of the components, variation in the viscosity, and melt-blending conditions [9].

Figure 4-7 shows the fractured surface of Sisal-PP composites at 10, 20 and $30 \mathrm{wt} \%$ fiber loading at 100, 200 RPM screw speed. Figure 5 gives a relatively smooth surface of PP matrix with a low percentage of sisal fiber after extrusion. But under closer observation (5000X), the presence of micro voids can be noted. These micro voids tend to make the composite brittle even though it gives a balanced strength distribution.

Figure 4, however has a higher percentage of the fiber (extruded under low screw speed) than the sample in figure 4. This higher percentage of the fiber increases the overall strength of the composite because of a greater fiber/matrix interaction. Figure 6 gives the SEM image of the fiber/matrix indicates a smoother surface than the others but under closer observation shows a granular formation of the PP matrix and voids in the composite which makes it brittle even with a high percentage of Sisal fiber. The composite shown in figure 7 shows a higher brittle nature of the composite indicated by higher fracture surfaces and granular formations. This further reduces the overall strength of the composite as compared to the previous one.

The Specimen prepared from the sisal fiber composite was subjected to mechanical tests like Tensile test, HDT, Impact and Flexural tests. The results of the experiments performed on four different specimens for each test is given below in Table 3 .
TABLE III.TENSILE TEST RESULTS ON SISAL FIBER COMPOSITE

\begin{tabular}{|c|c|c|c|}
\hline Comp ID & $\begin{array}{c}\text { Yield } \\
\text { Strength } \\
(\mathrm{MPa})\end{array}$ & \% Elongation & $\begin{array}{c}\text { Youngs' } \\
\text { Modulus } \\
(\mathrm{MPa})\end{array}$ \\
\hline PP10SF100 & 28.608 & 17.972 & 2543.40 \\
\hline PP20SF100 & 30.424 & 5.660 & 3403.80 \\
\hline PP20SF200 & 27.296 & 5.718 & 3250.80 \\
\hline PP30SF200 & 27.296 & 5.718 & 3250.80 \\
\hline
\end{tabular}

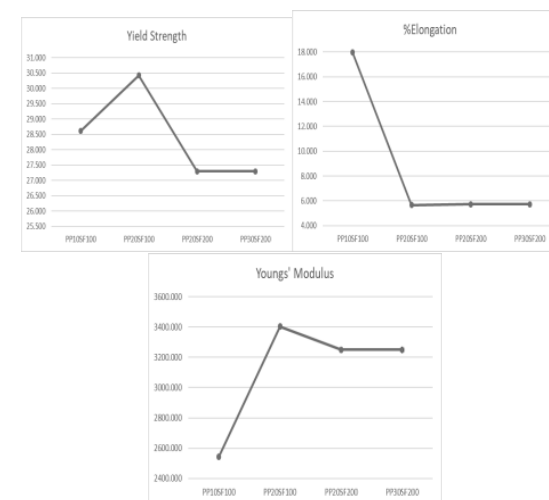

Fig. 8. Graphical Representation of Tensile test on sisal fiber composite.

Figure 8 shows the graphs for the tensile test performed on the sisal fiber composites for different Fiber percentages and screw speeds. The graphs indicate that the yield strength of the composite will be highest at a low feeder speed and high fiber percentage. \% Elongation of the fiber drops from a high value to a constant value for higher percentages of fiber and feeder speeds. Youngs' modulus is highest at a low feeder speed and high fiber percentage. The low feeder speeds increase the sisal fiber/Polypropylene interaction and hence improves the overall strength of the composites. But it should also be noted that higher speeds would reduce the fiber length in the composite.

\section{TABLE IV.HDT TEST RESULTS ON SISAL FIBER COMPOSITE}

\begin{tabular}{|c|c|}
\hline S1 No & $\begin{array}{c}\text { Deflection Temperature } \\
\left({ }^{\circ} \mathrm{C}\right)\end{array}$ \\
\hline 1 & 102.750 \\
\hline 2 & 127.950 \\
\hline 3 & 122.500 \\
\hline 4 & 133.000 \\
\hline
\end{tabular}

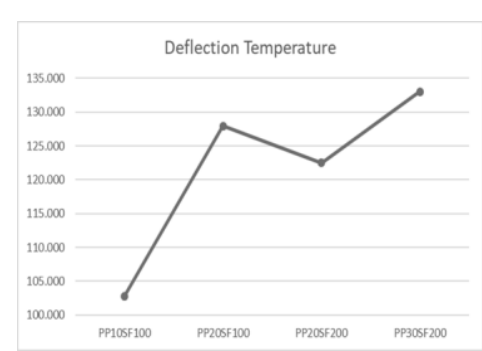

Fig. 9. Graphical Representation of HDT test on sisal fiber composite. 


\section{EFFECT OF FIBER CONTENT AND SCREW SPEED ON MECHANICAL CHARACTERIZATION OF SISAL FIBER REINFORCED POLYPROPYLENE COMPOSITES}

Figure 9 shows the graphs for the HDT test performed on the sisal fiber composites for different fiber percentages and screw speeds. The maximum fiber stress was kept constant at $0.445 \mathrm{MPa}$ and the test was conducted. The deflection temperature is lowest at the low percentages and low screw speed and increases to a certain value and reaching a maximum at high fiber percentage and high speeds. As seen from the graph, the deflection temperature is mainly dependent on the percentage reinforcing fiber in the PP matrix and also on the screw speed. The increase in fiber percentage increases the heat deflection temperature as the heat absorption capacity of the fiber/matrix composite will be increased due to the addition of sisal fiber to the PP matrix. This means that the composite produced can withstand to larger temperature range than previously possible.

TABLE V.FLEXURAL TEST RESULTS ON SISAL FIBER COMPOSITE

\begin{tabular}{|c|c|c|}
\hline S1 No & $\begin{array}{c}\text { Flexural Yield } \\
\text { (MPa) }\end{array}$ & $\begin{array}{c}\text { Flexural Modulus } \\
\text { (MPa) }\end{array}$ \\
\hline 1 & 49.484 & 3094.40 \\
\hline 2 & 49.562 & 4026.00 \\
\hline 3 & 45.818 & 3865.20 \\
\hline 4 & 55.680 & 6742.00 \\
\hline
\end{tabular}

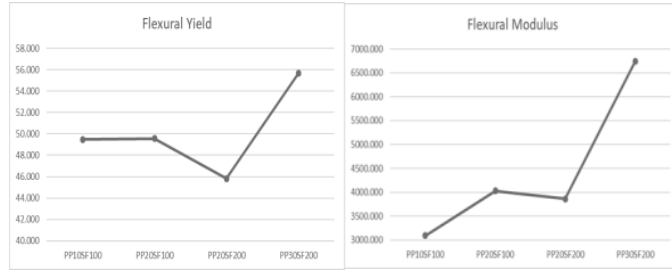

Fig. 10. Graphical Representation of Flexural test on sisal fiber composite.

Figure 10 shows the graph for the Flexural test performed on the sisal fiber composites for different fiber percentages and screw speeds. The graphs indicate that the maximum Flexural yield is obtained for high fiber percentage and high screw speeds and lowest is found at intermediate fiber percentage and high screw speeds. Flexural Modulus is highest at high screw speeds and high fiber percentage and lowest at low fiber percentage and low screw speeds. The increase in sisal fiber percentage in the PP matrix has a high influence on the flexural properties of the composite. This is because, the addition of fiber increases the strength of the composite as seen from the figure 10 .

TABLE VI. IMPACT TEST (UN-NOTCHED) RESULTS ON SISAL FIBER COMPOSITE

\begin{tabular}{|c|c|c|c|}
\hline $\begin{array}{c}\text { S1 } \\
\text { No }\end{array}$ & $\begin{array}{c}\text { Impact } \\
\text { Resistance } \\
(\mathrm{J} / \mathrm{m})\end{array}$ & $\begin{array}{c}\text { Impact } \\
\text { Strength } \\
\left(\mathrm{kJ} / \mathrm{m}^{\wedge} 2\right)\end{array}$ & $\begin{array}{c}\text { Impact } \\
\text { Energy } \\
(\mathrm{J})\end{array}$ \\
\hline 1 & 308.864 & 24.422 & 0.984 \\
\hline 2 & 247.104 & 19.558 & 0.791 \\
\hline 3 & 283.972 & 22.466 & 0.912 \\
\hline 4 & 214.214 & 16.952 & 0.693 \\
\hline
\end{tabular}

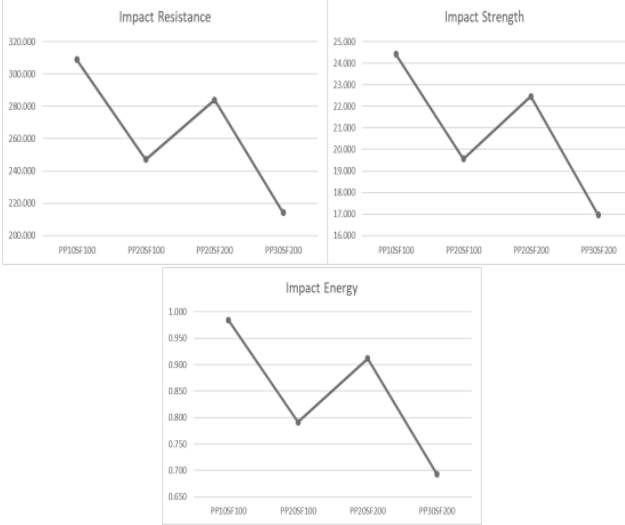

Fig. 11. Graphical Representation of Impact test on sisal fiber composite.

Figure 11 shows the graph for the Impact test performed as per ASTM D 4812 on the sisal fiber composites for different fiber percentages and screw speeds. The graphs indicate that the maximum Impact resistance, Impact strength and Impact Energy is obtained for low fiber percentage and low screw speeds and lowest is found at high fiber percentage and high screw speeds. The graph indicates that the impact resistance of the composite is mainly dependent on the percentage of the matrix in the composite since the majority of the impact load will be transferred to the matrix directly.

\section{TABLE VII.HARDNESS TEST RESULTS ON SISAL FIBER COMPOSITE}

\begin{tabular}{|c|c|}
\hline S1 No & Hardness \\
\hline 1 & 69.60 \\
\hline 2 & 71.00 \\
\hline 3 & 71.00 \\
\hline 4 & 70.80 \\
\hline
\end{tabular}

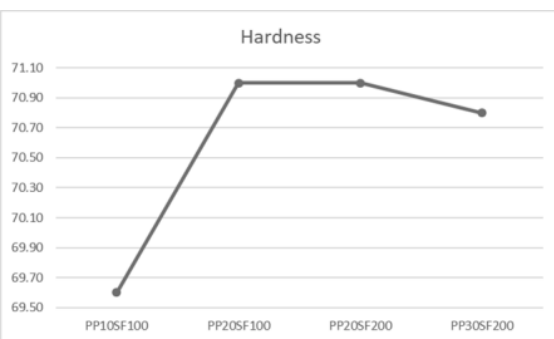

Fig. 12. Graphical Representation of Hardness test on sisal fiber composite.

Figure 12 shows the graph for the Hardness test performed as per ASTM standards on the sisal fiber composites for different fiber percentages and screw speeds. The graph indicates that the maximum BHN value is obtained for high fiber percentage and low screw speeds and lowest is found at low fiber percentage and low screw speeds. It also indicates that the screw speed during the manufacturing of the composite has very little effect on the hardness property of the composite. The deformation of the composite under a point load will be mainly dependent on the distribution of the fiber in the matrix and not on the screw speed. 


\section{CONCLUSIONS}

This paper demonstrates the effect of Sisal fiber reinforcement in the polypropylene matrix. First, chemical treatment was performed to reduce the hydrophilic nature of the sisal fibers. Then, the composites were produced using different percentages of sisal fiber at different extruder screw speeds which give a generalized understanding of the effect of fiber reinforcement in the plastic composite. The increase in the percentage of sisal fiber and the presence of compatibilizer decreased the number of micro voids during the extrusion process and also increased the inter facial bonding between the polypropylene matrix and the sisal fiber. This increase in the interfacial bonding increased the youngs modulus of the composite by $27.8 \%$, Flexural yield by $12.5 \%$, Flexural Modulus by $117 \%$ and the hardness of the composite improved by $1.7 \%$.

\section{REFERENCES}

1. Yu Y, Huang $\mathrm{X}, \mathrm{Yu} \mathrm{W}$. A novel process to improve yield and mechanical performance of bamboo fiber reinforced composite via mechanical treatments. Compos Part B: Eng. 2014; 56(1): 48-53.

2. Xie F, Pollet E, Halley PJ, et al. Starch-based nanobiocomposites. Prog Polym Sci. 2013; 38(10-11): 1590-1628.

3. Cotonieto-Morales MB, Palma-Rodríguez HM, ChavarríaHernández $\mathrm{N}$, et al. Partial characterization of chayotextle starch composites with added polyvinyl alcohol. Science. 2015; 67(3-4): 355-364.

4. Alvarez V, Vázquez A, Bernal C. Fracture behavior of sisal fiber-reinforced starch-based composites. Polym. Compo. 2010; 26(3): 316-323.

5. Seki Y. Innovative multifunctional siloxane treatment of jute fiber surface and its effect on the mechanical properties of jute/thermoset composites. Mater Sci Eng A. 2009; 508(1-2): 247-252.

6. Arbelaiz A, Cantero G, Fernández B, et al. Flax fiber surface modifications: effects on fiber physico mechanical and flax/polypropylene interface properties. Polym Compos. 2005; 26(3): 324-332.

7. Bozaci E, Sever K, Sarikanat M, et al. Effects of the atmospheric plasma treatments on surface and mechanical properties of flax fiber and adhesion between fiber-matrix for composite materials. Compos Part B: Eng. 2013; 45: 565572.

8. Höcker H. Plasma treatment of textile fibers. Pure Appl Chem. 2002; 74(3): 423-427.

9. Zafeiropoulos NE, Baillie CA, Hodgkinson JM. Engineering and characterisation of the interface in flax fibre/polypropylene composite materials. Part II. The effect of surface treatments on the interface. Compos Part A: Appl Sci Manufac. 2002; 33(9): 1185-1190.

10. Tran T, Bénézet JC. Rice and Einkorn wheat husks reinforced poly(lactic acid) (PLA) biocomposites: Effects of alkaline and silane surface treatments of husks. Ind Crops Prod. 2014; 58: $111-124$

11. A. K. Bledzki and J. Gassan, Composites Reinforced with Cellulose Based Fibres, Progress in Polymer Science 24 (1999) 221

12. Y. Li, Y.-W. Mai and L. Ye, Sisal Fibre and Its Composites: A Review of Recent Developments, Composites Science and Technology 60, (2000) 2037.

13. M. Suresh Babu, S. Baksi, G. Srikant and S. Biswas, Thermoplastic composites- A New Business Avenue, in http://www.tifac.org.in/news/acthermo.htm

14. M. Joshi, S. N. Maiti, A. Misra and R. K. Mittal, Polymer composites 15, (1994) 349.

15. T. Galea, T. Mills, R. Halliwell and K. Jayaraman, Screwless Extrusion of Natural Fibre-Reinforced Thermoplastic Composites, Composites Technologies for 2020 - Proceedings of the Fourth Asian-Australian Conference on Composite Materials, (2004), pp. 27-32.
16. Maxwell, B. and A. J. Scalora, Plastics Engineering 10, (1959) 107.

17. Z. Hashin, J. Appl. Mech. 50, (1983) 481-505.

18. Elmendorp, J.J.; Maalcke, R.J. A study on polymer blending microrheology: Part 1. Polym. Eng. Sci. 25, (1985) 10411047. 